\title{
Generation and Manipulation of Sodium Cationized Peptides in the Gas Phase
}

\author{
Kelly A. Newton and Scott A. McLuckey \\ Department of Chemistry, Purdue University, West Lafayette, Indiana, USA
}

\begin{abstract}
Sodiated peptides are often generated by electrospray ionization (ESI) of solutions containing peptides and a sodium salt. Fragmentation of singly sodiated, singly charged peptide ions commonly provides specific sequence information. However, these ions may be difficult to form by directly electrospraying a mixture. In the application of a recently described technique for forming metal containing peptide ions in the gas phase, singly sodiated, singly charged ions are formed via cation-switching ion/ion reactions of multiply protonated peptides. Proton transfer ion/ion reactions can also be used to form $[\mathrm{M}+\mathrm{Na}]^{+}$through the reduction of charge states of multiply charged, singly sodiated ions. The specificity and flexibility of the techniques employed provide a highly controlled means of generating sodiated peptide and protein ions. Thus, the methodologies presented here have potential for forming ions not readily observed via ESI or MALDI. Furthermore, the use of ion/ion reactions to form sodiated peptides facilitates direct comparisons of the fragmentation behavior of $\left[\mathrm{M}+\mathrm{Na}^{+}\right.$peptides formed in the absence of solvent with that of $\left[\mathrm{M}+\mathrm{Na}^{+}\right.$peptides generated by directly electrospraying a sodium salt/peptide mixture. Thus, in addition to descriptions of the formation of $[\mathrm{M}+\mathrm{Na}]^{+}$peptides in the gas phase using ion/ion reactions, results from CID of reaction products are presented herein. (J Am Soc Mass Spectrom 2004, 15, 607-615) () 2004 American Society for Mass Spectrometry
\end{abstract}

$\mathrm{T}$ Tandem mass spectrometry (MS/MS) of cationized peptides and proteins is a commonly used approach for obtaining primary sequence information. The fragmentation behavior of protonated peptides has been extensively examined. However, complementary fragmentation and/or specific sequence information may be obtained by performing collisioninduced dissociation experiments on metal cationized peptides. Several groups have reported the effects of using alkali metals or transition metals instead of protons as cationizing reagents on peptide fragmentation [1-4]. A potentially analytically useful observation from such studies is the possibility for C-terminal sequencing of peptides when sodium is the cationizing reagent [5-7].

Sodiated peptides are often generated by electrospray ionization (ESI) of solutions containing peptides and a sodium salt. Upon collision induced dissociation (CID) of sodiated peptides, $\left[\mathrm{b}_{\mathrm{n}-1}+\mathrm{Na}+\mathrm{OH}\right]^{+}$products, where $n$ represents the number of amino acid residues in the peptide, are commonly observed [2, $5-10]$. The $\left[b_{n-1}+\mathrm{Na}+\mathrm{OH}\right]^{+}$products are equivalent to a truncated version of the respective peptide without the C-terminal residue. Subsequent MS/MS of first generation $\left[b_{n-1}+\mathrm{Na}+\mathrm{OH}\right]^{+}$products may yield

Published online February 5, 2004

Address reprint requests to Dr. S. A. McLuckey, Department of Chemistry, Purdue University, 1393 Brown laboratory, 560 Oval Drive, West Lafayette, IN 47907-1393, USA. E-mail: mcluckey@purdue.edu
$\left[b_{m}+\mathrm{Na}+\mathrm{OH}\right]^{+}$ions, where $\mathrm{m}$ is one less than $(\mathrm{n}-1)$ $[5,6]$. Thus, MS $^{\mathrm{n}}$ of sodiated peptide ions can facilitate determination of peptide ion sequences through sequential cleavages corresponding to loss of C-terminal residues. Competition among fragmentation channels other than the one leading to formation of $\left[b_{n-1}+\mathrm{Na}+\right.$ $\mathrm{OH}]^{+}$constrains the ability to obtain complete sequence information, since abundance of the first and each subsequent $\left[\mathrm{b}_{\mathrm{n}-1}+\mathrm{Na}+\mathrm{OH}\right]^{+}$product limits the extent to which $\mathrm{MS}^{\mathrm{n}}$ can be performed and further sequence information acquired. Glish and co-workers have investigated factors that influence the abundance of $\left[b_{n-1}+\mathrm{Na}+\mathrm{OH}\right]^{+}$products in a study of sodiated peptide fragmentation [6]. They found that the identity of the C-terminal residue impacted the dissociation of singly charged, singly sodiated peptides more than any other factor. The mechanism for C-terminal fragmentation leading to the formation of $\left[b_{n-1}+\mathrm{Na}+\mathrm{OH}\right]^{+}$ products has been the subject of much investigation [6, 9-11]. A similar process is believed to be responsible for the observation of $\left[b_{n-1}+O H\right]^{+}$in MS/MS spectra of some protonated peptides containing arginine $[12,13]$. A recent study of the mechanism involved in C-terminal fragmentation of alkali metal cationized peptides suggests that formation of $\left[b_{n-1}+\text { Alkali }+\mathrm{OH}\right]^{+}$does not rely on the presence of an alkali metal [11]. Although the pathway leading to formation of $\left[b_{n-1}+\mathrm{Na}\right.$ $+\mathrm{OH}]^{+}$is still debated, it likely involves rearrangement and a 5-membered ring intermediate.

One factor limiting the applicability of gas phase 
C-terminal sequencing via tandem mass spectrometry of sodiated peptides is that the sequence informative $\left[b_{n-1}+\mathrm{Na}+\mathrm{OH}\right]^{+}$product is most commonly observed upon CID of singly charged, singly sodiated peptide ions [5-7]. Other fragmentation channels become competitive and their respective product ions are dominant in the MS/MS spectra for doubly charged sodiated peptide ions as well as peptides containing multiple sodium ions. When a sodium salt is added to the peptide solution for electrospray ionization, the resulting mass spectrum is comprised of a mixture of ions, varying in cationizing reagents and ion charge states. There is limited control over the number of singly charged, singly sodiated peptide ions generated. Since it becomes difficult to form singly charged, singly sodiated peptide ions for peptides greater than ten amino acid residues in length, gas-phase sequencing using MS/MS of sodiated peptides has primarily been successful with small peptides ( $<10$ residues) $[5,6]$. Matrix assisted laser desorption ionization (MALDI) is an alternate technique that can be used to form singly charged, singly sodiated peptide ions [14, 15]. MALDI has been used to form singly charged, singly sodiated peptide ions up to 16 residues using in length [14]. This method of ionization typically yields singly charged ions even for protein ions. The possibility of attachment of multiple sodium ions or other adducts to the singly charged ion could be a potential complication of using MALDI to form singly charged, singly sodiated ions of larger peptides and proteins. Thus, gas-phase sequencing using $\mathrm{MS}^{\mathrm{n}}$ of singly charged, singly sodiated peptides has not been reported for many ions above $1 \mathrm{kDa}$, presumably due to the difficulty in forming these ions.

Recently, a new strategy offering more control over formation of metal containing peptide ions than ESI and MALDI has been described. The approach involves gas-phase cation-switching ion/ion reactions in a quadrupole ion trap mass spectrometer equipped with multiple electrospray ionization sources [16]. The reactant ions are formed via ESI and are directed into separate ion sources allowing for independent optimization of solution and electrospray conditions. Therefore, this approach avoids signal suppression and dilution effects, which can be observed when polypeptide and metal salts are electrosprayed from the same solution. Another advantage of forming the reactant ions separately is that it facilitates the isolation of specific ions for participation in the ion/ion reactions. Products from the ion/ion reactions of selected reactants can be mass analyzed directly or isolated and subjected to CID prior to mass analysis.

In this paper, we describe the use of ion/ion reactions in a quadrupole ion trap to form and manipulate sodiated peptide ions in the gas phase. Cation-switching ion/ion reactions are used to generate sodium cationized peptide ions in the gas phase. Proton transfer ion/ion reactions are used to reduce the charge state of multiply charged, singly sodiated ions to +1 . Such ion/ion reactions facilitate direct comparisons of the fragmentation behavior of $[\mathrm{M}+\mathrm{Na}]^{+}$peptides formed in the absence of solvent with that of $[\mathrm{M}+\mathrm{Na}]^{+}$ peptides generated by directly nanospraying a sodium salt/peptide mixture. Furthermore, these techniques enable exploration of C-terminal peptide sequencing in the gas phase via $\mathrm{MS}^{\mathrm{n}}$ of singly charged, singly sodiated ions larger than those previously investigated. Thus, in addition to descriptions of the formation of $[\mathrm{M}+\mathrm{Na}]^{+}$ peptides in the gas phase using ion/ion reactions, results from CID of reaction products are presented herein.

\section{Experimental}

\section{Chemicals}

Sodium hydroxide, sodium nitrate, sodium diethyldithiocarbamate and perfluro-1,3-dimethylcyclohexane (PDCH) were purchased from Aldrich (St. Louis, MO). YGGFLK, substance $\mathrm{P}$, and Trp-11 neurotensin were obtained from BACHEM (King of Prussia, PA). KGAILAGAILR, VDPVNFK, GLSDEWQQVLNWGK were synthesized by SynPep (Dublin, CA). Bovine ubiquitin was purchased from Sigma (St. Louis, MO). Peptide and protein solutions $(\sim 0.1 \mathrm{mg} / \mathrm{mL})$ for nanospray ionization were prepared in $1 \%$ acetic acid. Sodium salts $(\sim 2.0 \mathrm{mg} / \mathrm{mL})$ were dissolved in water and nanosprayed directly. Typical nanospray voltages were $+1.5 \mathrm{kV}$ and $-1 \mathrm{kV}$, respectively. For comparative purposes, selected peptide/protein and sodium salt solutions were combined and nanosprayed.

\section{Instrumentation}

Gas-phase ion/ion reactions were performed using Finnigan ITMS (San Jose, CA) quadrupole ion traps modified with dueling electrospray ionization sources [17, 18]. A Hitachi M-8000 electrospray/ion trap mass spectrometer modified for proton transfer ion/ion reactions was also used [19]. Glow discharge ionization was used to form PDCH anions for participation in proton transfer ion/ion reactions. The experimental sequence began with accumulation of positive ions (200 $\mathrm{ms})$ followed by ion isolation $(60 \mathrm{~ms})$. Accumulation of negative ions ranged from $50 \mathrm{~ms}$ for $\mathrm{PDCH}$ to $400 \mathrm{~ms}$ for sodium diethyldithiocarbamate. Mutual ion storage times were typically $300-500 \mathrm{~ms}$. Residual anions were ejected from the trap using an RF ramp after the ion/ion reaction period. Isolation $(60 \mathrm{~ms})$ and CID (100 ms) were performed on selected ion/ion reaction products as well as metal containing peptide ions generated from solution. Mass analysis was achieved using resonance ejection. Ion/ion reaction product spectra and CID spectra were typically the average of 200 scans. 

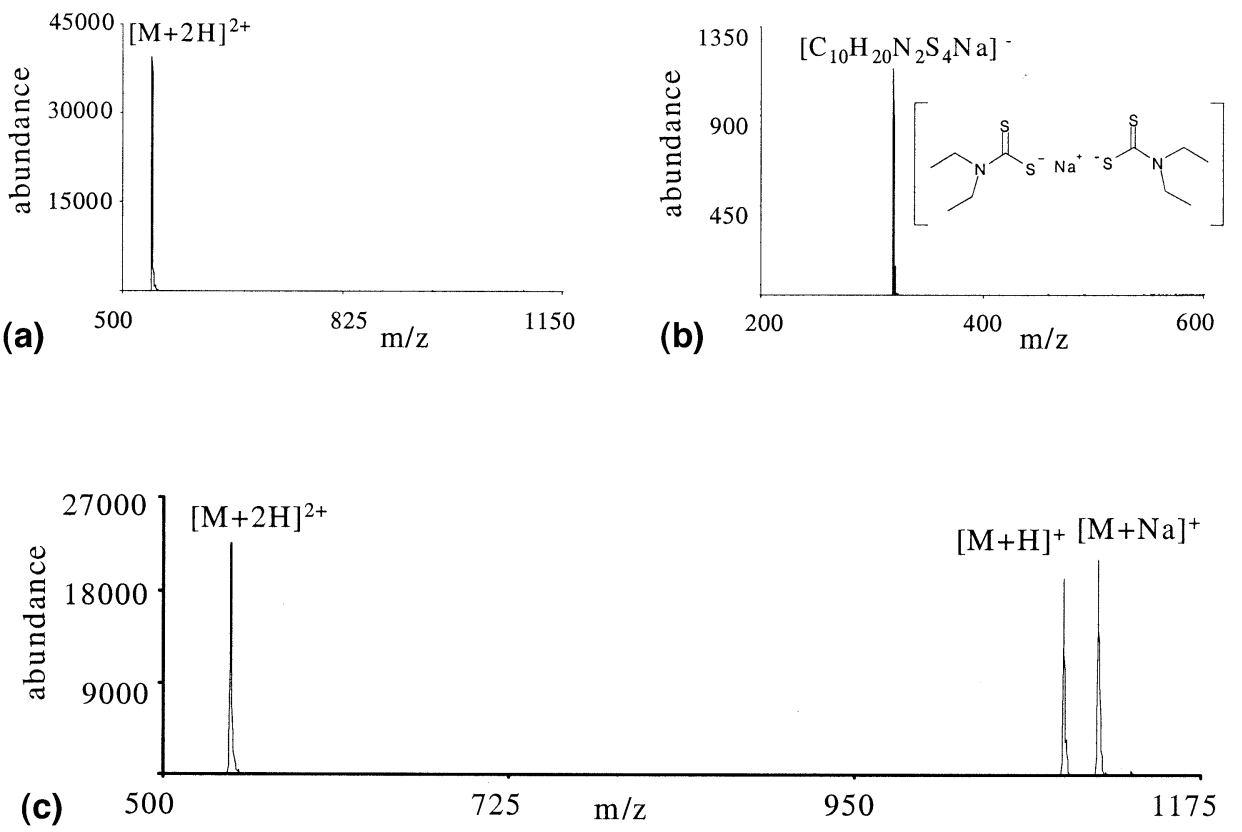

Figure 1. (a) MS of isolated [M $+2 \mathrm{H}]^{2+}$ KGAILAGAILR. (b) MS of sodium diethyldithiocarbamate anions. (c) Cation-switching ion/ion reaction product spectrum from the reaction of ions shown in (a) and $(\mathbf{b})$.

\section{Results and Discussion}

\section{General Strategies for Forming Sodiated Peptide Ions in the Gas Phase}

There are several means by which gas-phase ion/ion reactions could be used to facilitate the formation of sodium containing peptide ions. When using instrumentation with multiple electrospray sources, singly or multiply charged cations and anions are accessible for ion/ion reactions. In this paper, reactions of multiply charged cations with singly charged anions are described. These reactions lead to the formation of positively charged peptide product ions. In the case of cation-switching ion/ion reactions, which involve the reaction of a multiply protonated peptide with a metal containing anion, the sodiated peptide product ion results from transfer of a sodium cation to the peptide and protons to the counterions present in the sodiated anion reagent. When $\mathrm{PDCH}$ ions are used to reduce the charge state of a multiply protonated sodium containing peptide ion, the lower charge state ions arise from proton transfer reactions. Thus, different gas-phase mechanisms were utilized to form the $[\mathrm{M}+\mathrm{Na}]^{+}$ peptides described in this paper. As a demonstration that both types of ion/ion reactions can be employed to successfully form $[\mathrm{M}+\mathrm{Na}]^{+}$peptides in the gas phase, the formation of $[\mathrm{M}+\mathrm{Na}]^{+}$KGAILAGAILR is detailed below.

As described in a recent communication [16], cationswitching ion/ion reactions involve the reaction of a multiply protonated ion with a metal containing anion. When using cation-switching ion/ion reactions to form $[\mathrm{M}+\mathrm{Na}]^{+}$KGAILAGAILR, doubly protonated
KGAILAGAILR ions are reacted with anions from a sodium diethyldithiocarbamate solution.

The first step in the process is isolation of doubly protonated KGAILAGAILR from the initial positive ion electrospray distribution (Figure 1a). After isolation of the doubly protonated ions, sodium diethyldithiocarbamate anions are admitted into the ion trap (Figure 1b). During the accumulation of anions and a subsequent reaction period, the $[\mathrm{M}+2 \mathrm{H}]^{2+}$ KGAILAGAILR ions and sodium containing anions are simultaneously stored in the ion trap. Ion/ion reactions occur during simultaneous storage leading to the formation of several products. To end the reaction period, the sodium diethyldithiocarbamate anions are ejected from the ion trap prior to mass analysis. Positively charged products from this set of reactants arise from proton transfer to yield the $[\mathrm{M}+\mathrm{H}]^{+}$ion, and cation exchange involving addition of sodium to the peptide to yield the [M + $\mathrm{Na}]^{+}$ion (Figure 1c). In general, three types of reaction products are commonly observed when multiply protonated peptides or proteins undergo ion/ion reactions with metal containing anions of the form metalL ${ }_{2}^{-}$, where $\mathrm{L}$ is an anionic ligand. The three types of products include a proton transfer product, a metal ion transfer product, and a complex comprised of the peptide and all or part of the anionic reagent. The processes that lead to these products for sodium containing anions are summarized generically in Reactions 1-3:

$$
\begin{aligned}
& {[\mathrm{M}+2 \mathrm{H}]^{2+}+\mathrm{NaL}_{2}^{-} \rightarrow[\mathrm{M}+\mathrm{H}]^{+}+\mathrm{HL}+\mathrm{NaL}} \\
& {[\mathrm{M}+2 \mathrm{H}]^{2+}+\mathrm{NaL}_{2}^{-} \rightarrow[\mathrm{M}+\mathrm{Na}]^{+}+2 \mathrm{HL}}
\end{aligned}
$$



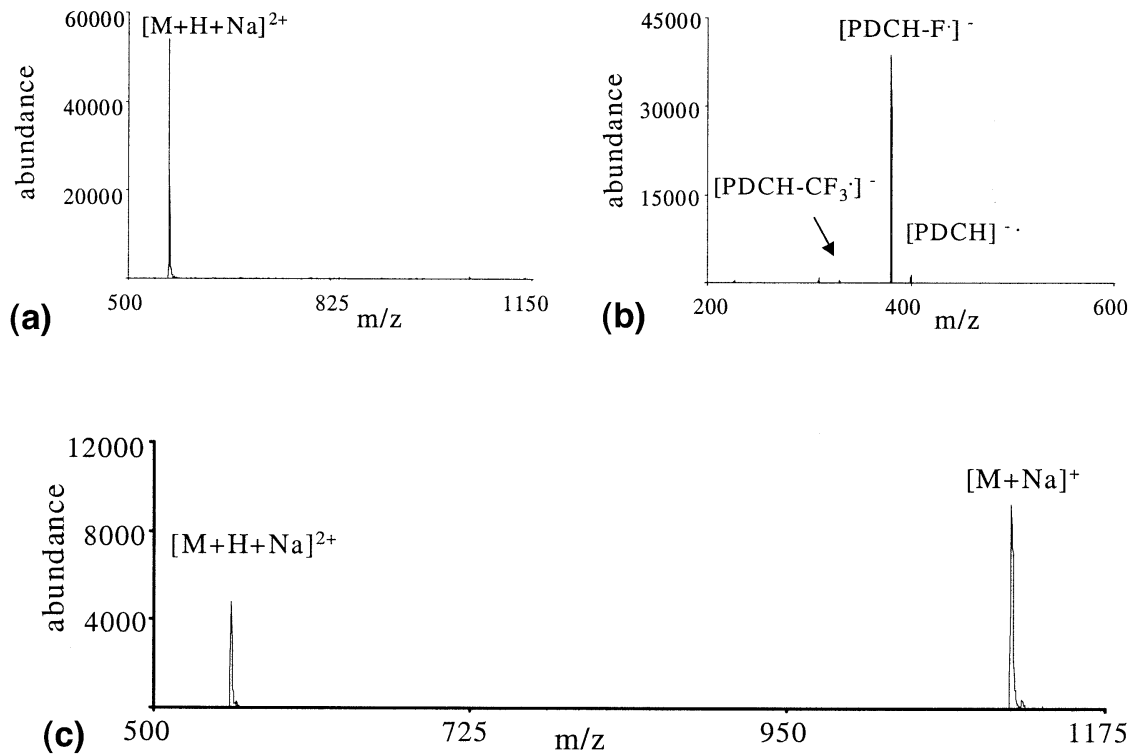

Figure 2. (a) MS of isolated [M $+\mathrm{Na}+\mathrm{H}]^{2+}$ KGAILAGAILR. (b) $\mathrm{MS}$ of PDCH anions. (c) Ion/ion reaction product spectrum from the reaction of ions shown in $(\mathbf{a})$ and $(\mathbf{b})$.

$$
[\mathrm{M}+2 \mathrm{H}]^{2+}+\mathrm{NaL}-\mathrm{L}_{2}^{-} \rightarrow\left[\mathrm{M}+2 \mathrm{H}+\mathrm{NaL}_{2}\right]^{+}
$$

Complex formation upon ion/ion reactions (Reaction 3) is a known phenomenon and has recently been discussed within the context of multiply charged cations in reactions with multiply charged anions [20]. It was demonstrated in that work that proton transfer and complex formation products are formed via competing mechanisms. Reaction 2 can proceed, at least in part, through the complex of Reaction 3. This conclusion follows from the fact that when a complex is formed, its collisional activation leads to loss(es) of HL, ultimately producing $[\mathrm{M}+\mathrm{Na}]^{+}$. The net effect of this process is a "switching" of one sodium ion for two protons of the peptide ion. In the case when $\mathrm{L}=$ the diethyldithiocarbamate anion, essentially no complex product, $[\mathrm{M}+$ $\left.2 \mathrm{H}+\mathrm{NaL}_{2}^{-}\right]^{+}$, is observed in the ion/ion reaction product spectrum. This is an advantage because it is then unnecessary to collisionally activate the complex product after the reaction period to form more of the sodium cationized peptide. Furthermore, when diethyldithiocarbamate served as the ligand in the anionic reagent used in the sodium cation-switching reaction, the yield of Reaction 2 was greater than that of Reaction 1 than for any other ligands evaluated thus far.

A second method in which gas-phase ion/ion reactions can be used to generate $[\mathrm{M}+\mathrm{Na}]^{+}$peptides is through the reduction of charge states of multiply protonated sodium containing peptide ions via proton transfer reactions. Two cation transfer reactions are possible for an ion with a mixture of protons and sodium ions as cationizing agents, as summarized by Reactions 4 and 5:

$$
[M+N a+H]^{2+}+X^{-} \rightarrow[M+N a]^{+}+H X
$$

$$
[\mathrm{M}+\mathrm{Na}+\mathrm{H}]^{2+}+\mathrm{X}^{-} \rightarrow[\mathrm{M}+\mathrm{Na}]^{+}+\mathrm{NaX}
$$

Perfluorocarbon anions, such as those formed from glow discharge ionization of $\mathrm{PDCH}$ vapors, are known to be effective reagents for removing protons from multiply protonated peptides and proteins [21, 22]. The strategy applied in forming $[\mathrm{M}+\mathrm{Na}]^{+}$peptides is to react multiply protonated, singly sodiated peptide ions with $\mathrm{PDCH}$ anions to sequentially remove protons, thereby producing singly sodiated +1 peptide ions. Although the initial sodium containing ions are formed in solution and electrosprayed, $[\mathrm{M}+\mathrm{Na}]^{+}$peptides arise from gas phase reactions.

In the case of generating $[\mathrm{M}+\mathrm{Na}]^{+}$KGAILAGAILR via this approach, $[\mathrm{M}+\mathrm{Na}+\mathrm{H}]^{2+}$ KGAILAGAILR is isolated from the initial ESI distribution of ions from a solution containing a sodium salt and the peptide (Figure 2a). After isolation, $\mathrm{PDCH}$ anions (Figure 2b) are introduced into the ion trap and allowed to react with $[\mathrm{M}+\mathrm{Na}+\mathrm{H}]^{2+}$ KGAILAGAILR. As shown in Figure $2 \mathrm{c}$, the only reaction product is $[\mathrm{M}+\mathrm{Na}]^{+}$, resulting from transfer of a proton from the peptide to a PDCH ion. There is no evidence of $[\mathrm{M}+\mathrm{H}]^{+}$reaction products, which would correspond to transfer of a sodium ion from the peptide to a PDCH anion. This is a key observation since it suggests that proton transfer reactions with $\mathrm{PDCH}$ can be used to reduce charge states of multiply charged sodiated peptide ions without the loss of sodium ions.

To evaluate the selectivity of $\mathrm{PDCH}$ anions for removal of protons from protein ions, a multiply charged sodium containing protein ion was reacted with the proton transfer reagent, $\mathrm{PDCH}$. The ESI distribution for a solution $(50 \%$ water $/ 50 \% \mathrm{MeOH} \mathrm{v} / \mathrm{v})$ containing sodium hydroxide and ubiquitin consisted of several 

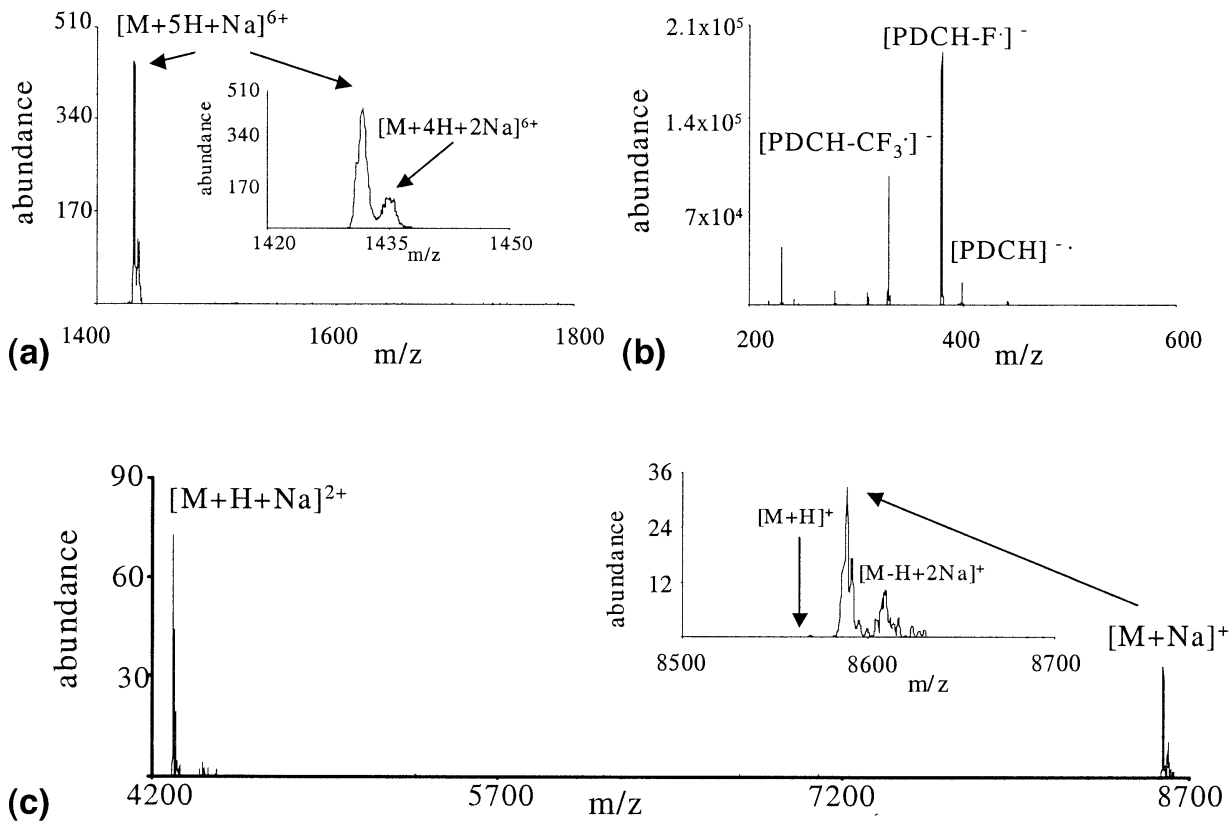

Figure 3. (a) $\mathrm{MS}$ of isolated $[\mathrm{M}+\mathrm{Na}+5 \mathrm{H}]^{6+}$ and $[\mathrm{M}+2 \mathrm{Na}+4 \mathrm{H}]^{6+}$ ubiquitin. (b) $\mathrm{MS}$ of PDCH anions. (c) Ion/ion reaction product spectrum from the reaction of ions shown in (a) and (b). The inserts show the relative amounts of singly sodiated and doubly sodiated ions.

protonated and sodiated ions. $[\mathrm{M}+5 \mathrm{H}+\mathrm{Na}]^{6+}$ and $[\mathrm{M}$ $+4 \mathrm{H}+2 \mathrm{Na}]^{6+}$ (Figure 3a) were isolated from this distribution and reacted with PDCH anions (Figure 3b).

The reaction time was sufficient for the formation of +1 ions. Singly charged, sodiated ubiquitin ions were observed and there there was no evidence for singly protonated ubiquitin ions in the reaction product spectrum (Figure 3c). A comparison of the relative ratios of singly sodiated ions to doubly sodiated ions in the inserts of Figure 3a and c revealed that the presence of multiple sodiums did not impact the tendency for PDCH ions to abstract protons rather than sodium ions. Thus, the sodium ions remained bound to the protein and were not removed after five consecutive reactions with the PDCH anions. Furthermore, there was little evidence for loss of sodium when a population of multiply charged ubiquitin ions containing 1-11 sodiums was reacted with PDCH ions (data not shown). These results provided additional evidence for the strong preference of $\mathrm{PDCH}$ anions for the removal of $\mathrm{H}^{+}$relative to removal of $\mathrm{Na}^{+}$from peptide and protein ions with mixtures of the two cationizing agents.

\section{CID of Sodiated Peptide Ions Formed in the Gas Phase}

The data of Figures 1-3 demonstrate the formation of singly charged, singly sodiated peptide ions in the gas phase via ion/ion reactions. As mentioned above, the fragmentation behavior of $[\mathrm{M}+\mathrm{Na}]^{+}$peptides generated in the gas phase is also of interest.

The MS/MS spectra of [M $+\mathrm{Na}]^{+}$KGAILAGAILR formed by the two types of ion/ion reactions as de- scribed above are shown in Figure 4. The ions formed via cation-switching reactions (Figure $4 \mathrm{a}$ ) and the ions resulting from proton transfer ion/ion reactions (Figure $4 b)$ fragment similarly. The major product ion in both spectra is $\left[b_{10}+\mathrm{Na}+\mathrm{OH}\right]^{+}$. This ion corresponds to loss of the C-terminal residue and suggests that ions formed in the gas phase using ion/ion reactions may be suitable for gas-phase sequencing strategies that employ $\mathrm{MS}^{\mathrm{n}}$ of sodiated peptides. Although it is noteworthy that there are no major differences in the MS/MS spectra of $[\mathrm{M}+\mathrm{Na}]^{+}$KGAILAGAILR formed using two different types of gas phase methods, the more attractive comparison would be with the fragmentation behavior of $[\mathrm{M}+\mathrm{Na}]^{+}$peptides from solution. However, such a comparison was not available for this peptide since $[\mathrm{M}+\mathrm{Na}]^{+}$was not observed when a mixture of a sodium salt and KGAILAGAILR was nanosprayed.

Other peptides were examined to determine the equivalency, or lack thereof, of sodiated peptides formed via electrospray and those formed via ion/ion reactions. Peptides yielding both $[\mathrm{M}+\mathrm{Na}]^{+}$and $[\mathrm{M}+$ $2 \mathrm{H}]^{2+}$ from nanospray ionization of solutions containing peptides and sodium salts were chosen. Cationswitching ion/ion reactions featuring these peptides were used to form $[\mathrm{M}+\mathrm{Na}]^{+}$in the gas phase, allowing a direct comparison of CID of $[\mathrm{M}+\mathrm{Na}]^{+}$ions formed from the same peptide in solution and in the gas phase. As an example of data collected for this comparative analysis, the fragmentation of $[\mathrm{M}+\mathrm{Na}]^{+}$YGGFLK is shown in Figure 5.

The MS/MS spectrum of $[\mathrm{M}+\mathrm{Na}]^{+}$YGGFLK from nanospray ionization of a solution containing YGGFLK 

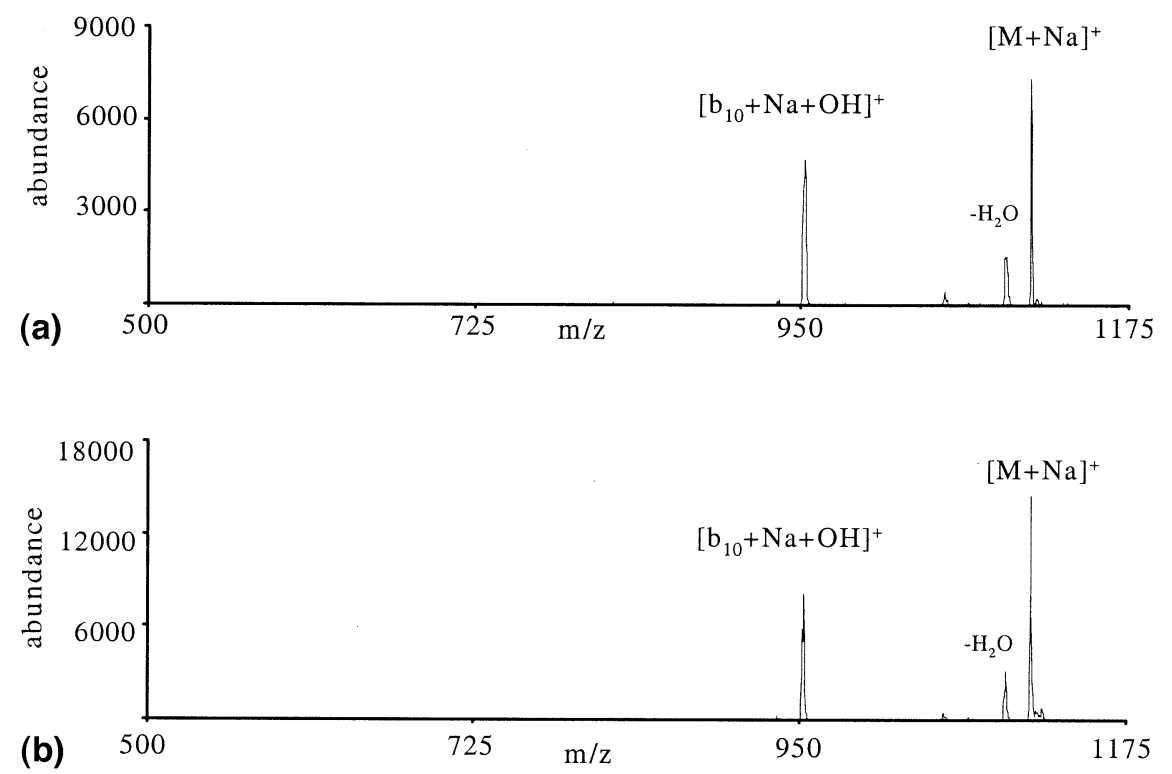

Figure 4. (a) MS/MS spectrum of $[\mathrm{M}+\mathrm{Na}]^{+}$KGAILAGAILR formed by cation-switching ion/ion reactions. (b) $\mathrm{MS} / \mathrm{MS}$ spectrum of $[\mathrm{M}+\mathrm{Na}]^{+}$KGAILAGAILR formed by proton transfer ion/ion reactions.

and a sodium salt is shown in Figure 5a. The MS/MS spectrum of $[\mathrm{M}+\mathrm{Na}]^{+}$YGGFLK formed in the gas phase via cation switching in a manner similar to that described for $[\mathrm{M}+\mathrm{Na}]^{+}$KGAILAGAILR is given in Figure $5 \mathrm{~b}$. The major product observed in each spectrum is $\left[\mathrm{b}_{5}+\mathrm{Na}+\mathrm{OH}\right]^{+}$. A MS ${ }^{3}$ spectrum of $[\mathrm{M}+$ $\mathrm{Na}]^{+}$formed by cation switching is shown in Figure $5 \mathrm{c}$. The major product is $\left[\mathrm{b}_{4}+\mathrm{Na}+\mathrm{OH}\right]^{+}$, which is also the major product ion observed upon $\mathrm{MS}^{3}$ of $[\mathrm{M}+\mathrm{Na}]^{+}$ from solution (data not shown). The observation of two consecutive losses of respective C-terminal residues in the $\mathrm{MS}^{3}$ experiments implies that if a $[\mathrm{M}+\mathrm{Na}]^{+}$ peptide generated from solution can be successfully sequenced via $\mathrm{MS}^{\mathrm{n}}$, the $[\mathrm{M}+\mathrm{Na}]^{+}$peptide generated in the absence of solvent using cation-switching reactions can be as well. That is, the ions formed in different ways are equivalent in terms of fragmentation behavior, at least under ion trap collisional activation conditions. Similar observations have been noted for multiply protonated species. Whenever MS/MS spectra of a
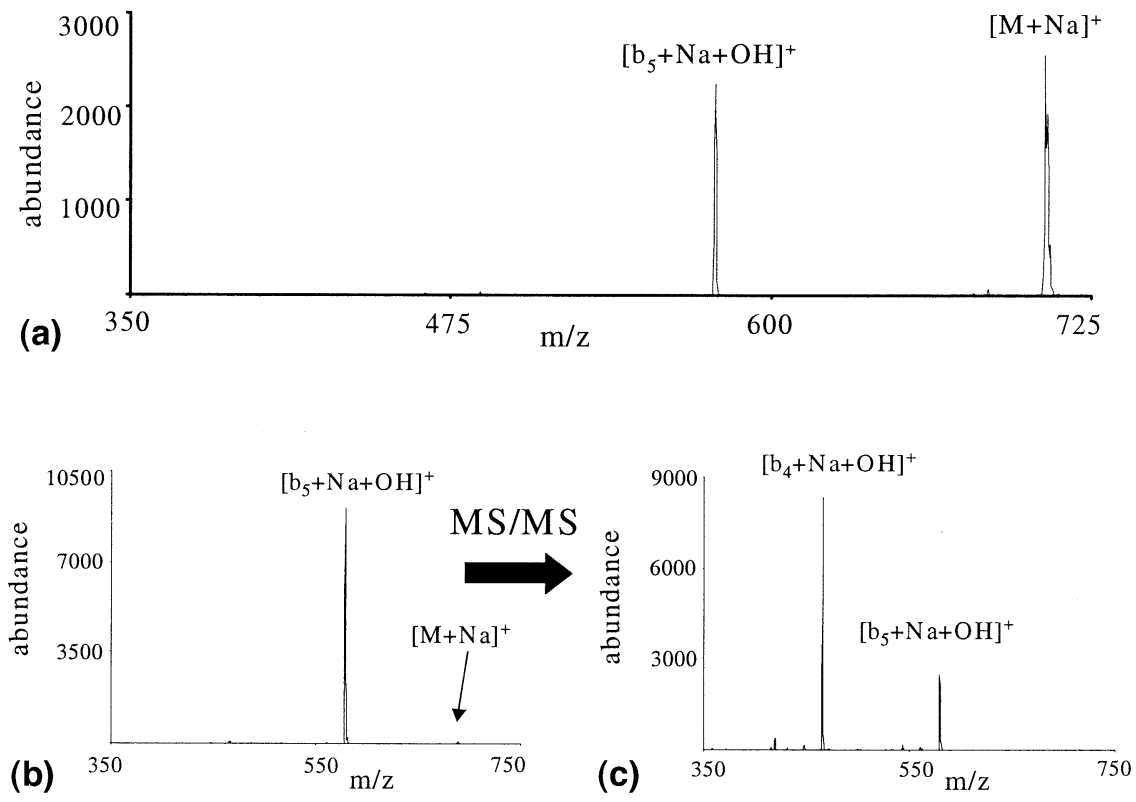

Figure 5. (a) MS/MS spectrum of $[\mathrm{M}+\mathrm{Na}]^{+}$YGGFLK from solution. (b) MS/MS spectrum of [M $+\mathrm{Na}^{+}$YGGFLK formed by cation-switching ion/ion reactions. (c) $\mathrm{MS}^{3}$ spectrum of $[\mathrm{M}+\mathrm{Na}]^{+}$ YGGFLK formed by cation-switching ion/ion reactions. 

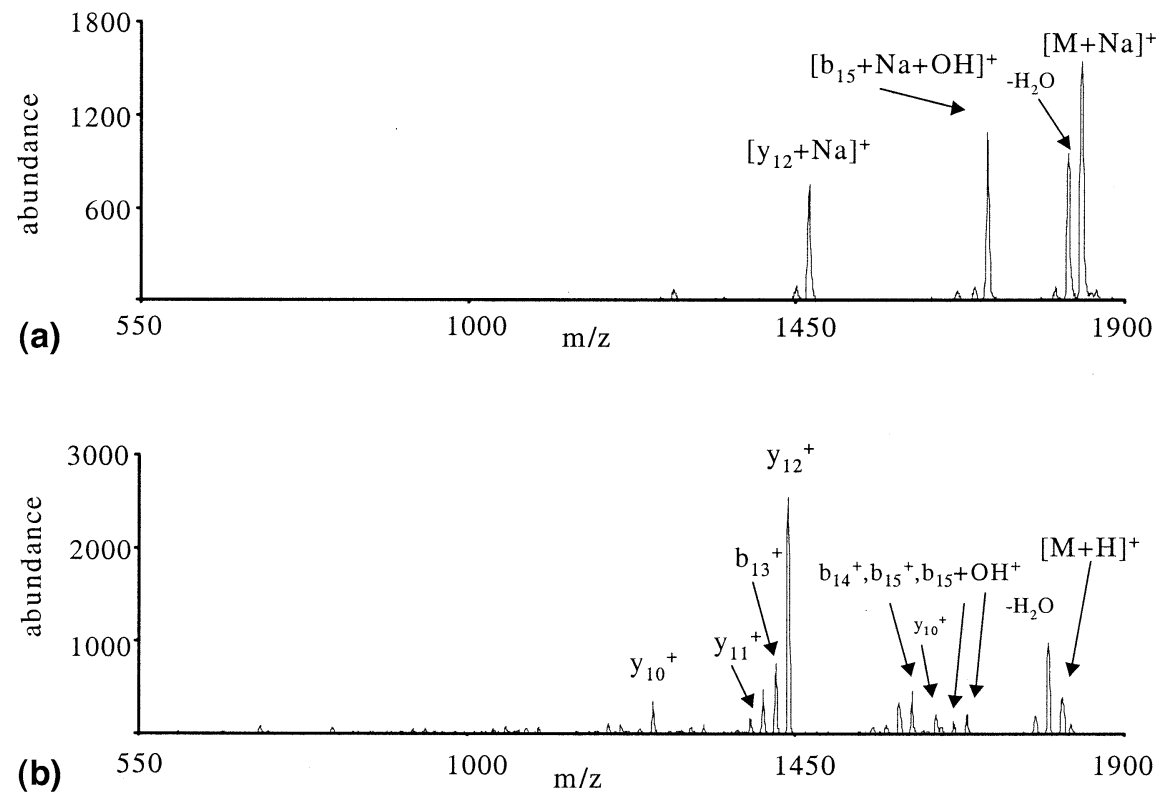

Figure 6. (a) MS/MS spectrum of $[\mathrm{M}+\mathrm{Na}]^{+}$GLSDGEWQQVLNVWGK formed by cation-switching ion/ion reactions. (b) MS/MS spectrum of $[\mathrm{M}+\mathrm{H}]^{+}$GLSDGEWQQVLNVWGK from solution.

protonated peptide or protein ion generated by proton transfer ion/ion reactions has been compared to that of the same nominal ion formed from solution, no distinct differences in the spectra have been noted [23].

As mentioned above, singly sodiated, singly charged peptide ions are most likely to undergo dissociation allowing C-terminal peptide sequencing from $\mathrm{MS}^{\mathrm{n}}$ experiments. Since methods have been developed to form sodium containing peptide ions in the gas phase, and the CID of these ions is comparable with that of ions from solution the possibilities for gas phase C-terminal sequencing was evaluated for peptides larger than those normally studied. Cation-switching ion/ion reactions were used to form $\left[\mathrm{M}+\mathrm{Na}^{+}\right.$of peptides for which such ions were not observed from directly nanospraying a sodium salt and peptide mixture. These peptides were at least ten residues in length, with molecular weights above $1 \mathrm{kDa}$. Results from CID of these $[\mathrm{M}+\mathrm{Na}]^{+}$peptides are given below.

When performing MS/MS on $[\mathrm{M}+\mathrm{Na}]^{+}$Trp-11 neurotensin, a product ion corresponding to loss of the C-terminal residue was not observed. Instead, water loss was a major product and several other fragments were present. The smaller fragments corresponded to sodiated versions of product ions observed in the MS/MS spectrum of $[\mathrm{M}+\mathrm{H}]^{+}$. Neutral losses were also prominent in MS/MS spectra of $[\mathrm{M}+\mathrm{Na}]^{+}$peptides featuring methyl esterified C-termini. In the case of $[\mathrm{M}+\mathrm{Na}]^{+}$substance $\mathrm{P}$, a peptide with an amidated C-terminus, neutral losses and sodiated C-terminal products were present in the MS/MS spectra. The fragmentation patterns observed for these larger sodiated peptides varied based on the composition of the respective peptide. In several cases, no new sequence information was obtained by forming and fragmenting the $[\mathrm{M}+\mathrm{Na}]^{+}$peptide. The absence of $\left[b_{n}+\mathrm{Na}+\right.$ $\mathrm{OH}]^{+}$CID products in the MS/MS spectra of these sodiated peptides suggests that $\mathrm{MS}^{\mathrm{n}}$ of $[\mathrm{M}+\mathrm{Na}]^{+}$ peptides to achieve C-terminal sequencing in the gas phase is not a strategy that can be universally extended to peptides above $1 \mathrm{kDa}$.

Studies reported by Beauchamp and co-workers showed that CID of singly charged, singly sodiated peptides containing acidic residues gave highly specific cleavages C-terminal to the acidic residues [14]. Perhaps, larger singly charged sodiated peptides will also preferentially fragment $\mathrm{C}$-terminal to acidic residues thereby revealing the location of the aspartic acid residues. Such specific information coupled with the mass of the peptide could be useful in correctly identifying peptides in tryptic digests of unknown proteins. The peptide, $[\mathrm{M}+\mathrm{Na}]^{+}$GLSDGEWQQVLNVWGK, was investigated since it is larger than those previously studied and also representative of a tryptic peptide containing acidic residues. The singly charged, singly sodiated ion was formed using cation-switching ion/ ion reactions. Upon CID of the $\left[\mathrm{M}+\mathrm{Na}^{+}\right.$parent ion, the major fragments observed were water loss, $\left[b_{15}+\right.$ $\mathrm{Na}+\mathrm{OH}]^{+}$(loss of the C-terminal residue), and $\left[\mathrm{y}_{12}+\right.$ $\mathrm{Na}^{+}{ }^{+}$(cleavage C-terminal to aspartic acid) (Figure 6a). In the MS/MS spectrum of the protonated version of this peptide (Figure $6 \mathrm{~b}$ ), $\mathrm{y}_{12}^{+}$is the dominant ion, while many other fragments are present.

When comparing the two MS/MS spectra, the sodiated ion spectrum is less complicated and has fragments providing specific sequence information. The same procedure and comparison was performed using a smaller tryptic peptide, VDPVNFK. Again, the MS/MS spectrum of the sodiated ion contained highly specific information with $\left[\mathrm{y}_{5}+\mathrm{Na}^{+}\right.$and $\left[\mathrm{b}_{6}+\mathrm{Na}+\right.$ 
$\mathrm{OH}]^{+}$as the major ions. Hence, the sodium cationized peptides formed via ion/ion cation switching reactions appear to show the same behavior related by other workers with peptide ions containing aspartic acid residues formed via electrospray and MALDI. These results, in conjunction with those related above, provide further evidence that when subjected to collisional activation in an ion trap, essentially equivalent fragmentation behavior can be expected whether the sodium cationized peptides are formed via ion/ion reactions or other methods.

\section{Conclusions}

The formation of sodiated peptide ions using cationswitching ion/ion reactions has been demonstrated. The use of diethyldithiocarbamate as the anionic ligand in sodium containing reagents is particularly advantageous in that products containing the metal-ligand complex are minimal and metal ion transfer is competitive with proton transfer. Another route to the formation of singly charged sodium cationized peptides is via the selective abstraction of protons from peptide and protein ions that contain mixtures of protons and sodium ions. Perfluorocarbon anions, such as those derived from glow discharge of $\mathrm{PDCH}$, selectively remove protons when mixtures of sodium ions and protons are present. CID of ion/ion reaction product ions of the form $[\mathrm{M}+\mathrm{Na}]^{+}$yields essentially identical product ion spectra regardless of whether they are formed via a cation-switching reaction or via proton abstraction from a multiply charged ion that contains a sodium cation. Furthermore, $[\mathrm{M}+\mathrm{Na}]^{+}$reaction products fragment similarly to those formed by nanospray ionization of solutions containing the peptide and a sodium salt. These results are consistent with observations in ongoing investigations of interactions of other metals with peptide and protein ions in the gas phase. Cationswitching ion/ion reactions and proton transfer ion/ ion reactions, therefore, provide new means for the formation of sodium containing peptides and proteins in the gas phase.

When cation-switching ion/ion reactions and proton transfer ion/ion reactions are used to form sodiated peptides and proteins, several distinct advantages are realized. Some of the benefits of this approach emerge from the utilization of multisource instrumentation to facilitate gas-phase ion chemistry experiments. In general, ESI sources allow a great deal of flexibility in terms of the protonated peptide and protein ions as well as sodium salt anions that can be selected for participation in ion/ion reactions. Since solution compositions can be optimized independently when separate ionization sources are used to form the reactant ions, the deleterious effects associated with adding salts to electrospray solutions are avoided. Utilization of multiple ion sources also allows for independent selection of ions of both polarities prior to the ion/ion reaction. The ability to form sodiated peptide ions within the context of a tandem mass spectrometry experiment allows specificity in terms of the products formed. Any multiply charged peptide ion population, including CID product ions, can be selected and reacted with the singly charged anions. As shown here, particularly in the reactions with $\mathrm{PDCH}$ anions, gas-phase ion chemistry can add a further dimension of specificity in the formation of ion/ion reaction products. The ability to perform ion/ion reactions in series offers additional freedom in generating a particular sodiated peptide or protein ion. For example, proton transfer reactions could be used to manipulate the charge state of ions prior to cationswitching reactions. The overall flexibility associated with using ion/ion reactions to form sodiated biological ions results from using multiple electrospray ionization sources and tandem in time ion manipulation techniques. The high degree of selectivity related to this approach is a function of the ability to choose and isolate reactants prior to the ion/ion reaction as well as the inherent selectivity of gas-phase ion chemistry.

\section{Acknowledgments}

This research was sponsored by the Division of Chemical Sciences, Geosciences, and Biosciences, Office of Basic Energy Sciences, U.S. Department of Energy, under Award No. DE-FG02-00ER15105.

\section{References}

1. Teesch, L. M.; Adams, J. Intrinsic Interactions Between Alkaline Earth Metal Ions and Peptides: A Gas-Phase Study. J. Am. Chem. Soc. 1990, 112, 4110-4120.

2. Grese, R. P.; Cerny, R. L.; Gross, M. L. Metal Ion-Peptide Interactions in the Gas Phase: A Tandem Mass Spectrometry Study of Alkali Metal Cationized Peptides. J. Am. Chem. Soc. 1989, 111, 2835-2842.

3. Hu, P.; Sorensen, C.; Gross, M. L. Influences of Peptide Side Chains on the Metal Ion Binding Site in Metal Ion-Cationized Peptides: Participation of Aromatic Rings in Metal Chelation. J. Am. Soc. Mass Spectrom. 1995, 6, 1079-1085.

4. Hu, P.; Loo, J. A. Gas-Phase Coordination Properties of $\mathrm{Zn}^{2+}$, $\mathrm{Cu}^{2+}, \mathrm{Ni}^{2+}$, and $\mathrm{Co}^{2+}$ with Histidine-Containing Peptides. J. Am. Chem. Soc. 1995, 117, 11314-11319.

5. Lin, T.; Glish, G. L. C-Terminal Peptide Sequencing via Multistage Mass Spectrometry. Anal. Chem. 1998, 70, 5162 5165.

6. Lin, T.; Payne, A. H.; Glish, G. L. Dissociation Pathways of Alkali-Cationized Peptides: Opportunities for C-Terminal Peptide Sequencing. J. Am. Soc. Mass Spectrom. 2001, 12, 497-504.

7. Lin, T.; Payne, A. H.; Glish, G. L. C-Terminal Peptide Sequencing using Acetylated Peptides with $\mathrm{MS}^{\mathrm{n}}$ in a Quadrupole Ion Trap. Analyst 2000, 125, 635-640.

8. Renner, D.; Spiteller, G. Linked Scan Investigation of Peptide Degradation Initiated by Liquid Secondary Ion Mass Spectrometry. Biomed. Environ. Mass Spectrom. 1988, 15, 75-77.

9. Tang, X.; Ens, W.; Standing, K. G.; Westmore, J. B. Daughter Ion Mass Spectra from Cationized Molecules of Small Oligopeptides in a Reflecting Time-of-Flight Mass Spectrometer. Anal. Chem. 1988, 60, 1791-1799.

10. Kulik, W.; Heerma, W.; Terlouw, J. K. A Novel Fragmentation Process in the Fast-Atom Bombardment/Tandem Mass Spectra of Peptides Cationized with $\mathrm{Na}^{+}$, Determining the Identity 
of the C-Terminal Amino Acid. Rapid Commun. Mass Spectrom. 1989, 3, 276-279.

11. Feng, W. Y.; Gronert, S.; Fletcher, K. A.; Warres, A.; Lebrilla, C. B. The Mechanism of C-Terminal Fragments in Alkali Metal Ion Complexes of Peptides. Int. J. Mass Spectrom. 2003, 222, 117-134.

12. Thorne, G. C.; Ballard, K. D.; Gaskell, S. J. Metastable Decomposition of Peptide $[\mathrm{M}+\mathrm{H}]^{+}$Ions via Rearrangement Involving Loss of the C-Terminal Amino Acid Residue. J. Am. Soc. Mass Spectrom. 1990, 1, 249-257.

13. Gonzalez, J.; Besada, V.; Garay, H.; Reyes, O.; Padron, G.; Tambara, Y.; Takao, T.; Shimonishi, Y. Effect of the Position of a Basic Amino Acid on C-Terminal Rearrangement of Protonated Peptides upon Collision-Induced Dissociation. J. Mass Spectrom. 1996, 31, 150-158.

14. Lee, S.-W.; Kim, H. S.; Beauchamp, J. L. Salt Bridge Chemistry Applied to Gas-Phase Peptide Sequencing: Selective Fragmentation of Sodiated Gas-Phase Peptide Ions Adjacent to Aspartic Acid Residues. J. Am. Chem. Soc. 1998, 120, 3188-3195.

15. Tomlinson, M. J.; Scott, J. R.; Wilkins, C. L.; Wright, J. B.; White, W. E. Fragmentation of an Alkali Metal-Attached Peptide Probed by Collision-Induced Dissociation Fourier Transform Mass Spectrometry and Computational Methodology. J. Mass Spectrom. 1999, 34, 958-968.

16. Newton, K. A.; McLuckey, S. A. Gas-Phase Peptide/Protein Cationizing Agent Switching via Ion/Ion Reactions. J. Am. Chem. Soc. 2003, 125, 12404-12405.
17. Wells, J. M.; Chrisman, P. A.; McLuckey, S. A. Dueling Electrospray: Instrumentation to Study Ion/Ion Reactions of Electrospray-Generated Cations and Anions. J. Am. Soc. Mass Spectrom. 2002, 13, 614-622.

18. Badman, E. R.; Chrisman, P. A.; McLuckey, S. A. A Quadrupole Ion Trap Mass Spectrometer with Three Independent Ion Sources for the Study of Gas-Phase Ion/Ion Reactions. Anal. Chem. 2002, 74, 6237-6243.

19. Reid, G. E.; Wells, J. M.; Badman, E. R.; McLuckey, S. A. Performance of a Quadrupole Ion Trap Mass Spectrometer Adapted for Ion/Ion Reaction Studies. Int. J. Mass Spectrom. 2003, 222, 243-258.

20. Wells, J. M.; Chrisman, P. A.; McLuckey, S. A. Formation and Characterization of Protein-Protein Complexes in Vacuo. J. Am. Chem. Soc. 2003, 125, 7238-7249.

21. Stephenson, J. L., Jr.; McLuckey, S. A. Ion/Ion Reactions in the Gas-Phase: Proton Transfer Reactions Involving MultiplyCharged Proteins. J. Am. Chem. Soc. 1996, 118, 7390-7397.

22. Stephenson, J. L., Jr.; McLuckey, S. A. Ion/Ion Reactions for Oligopeptide Mixture Analysis: Application to Mixtures Comprised of 0.5-100 kDa Components. J. Am. Soc. Mass Spectrom. $1998,9,585-596$.

23. Newton, K. A.; Chrisman, P. A.; Wells, J. M.; Reid, G. E.; McLuckey, S. A. Gaseous Apomyoglobin Ion Dissociation in a Quadrupole Ion Trap: $(\mathrm{M}+2 \mathrm{H})^{2+}-(\mathrm{M}+21 \mathrm{H})^{21+}$. Int. J. Mass Spectrom. 2001, 212, 359-376. 